\title{
DE LA RETÓRICA A LA HISTORIA: LA PROSA HISTORIOGRÁFICA DE ÉFORO
}

\author{
FROM RHETORIC TO HISTORY: \\ THE HISTORIOGRAPHIC PROSE OF EPHORUS
}

\author{
José Antonio Caballero López \\ Universidad de La Rioja \\ antonio.caballero@unirioja.es
}

DOI: $10.1387 /$ veleia.14967

\begin{abstract}
Resumen: En el presente trabajo mostramos cómo, por mediación de Isócrates, la retórica influyó no solo en la forma de relatar los hechos históricos sino incluso en la propia selección del material historiable. Estudiamos particularmente la obra historiográfica de Éforo, que fue discípulo de Isócrates, y comprobamos, ciertamente, la impronta que la «retórica escolar» de su maestro dejó en las Historias, tanto en la preocupación estilística como en la concepción didáctico-moral de la historiografía. Sin embargo, nuestro autor es consciente de que no está componiendo un discurso, sino una obra de historia; y lo que se señala como pobre imitación del estilo isocrático no sería sino autorregulación propia y cierta fidelidad a las formas tradicionales del género historiográfico.

Palabras clave: Éforo, Isócrates, historiografía retórica.

Abstract: In this paper we show the way in which Rhetoric influenced, through Isocrates, not only the form of writing historical facts, but also the proper selection of historical topics. Particularly, we studied the historiographical work of Ephorus, who was a disciple of Isocrates. The "school rhetoric» of his master left its mark in his Histories, regarding both the stylistic concern and the didactic moral concept of historiography. However, our author is aware that he is not composing a speech, but a work of history; and what has been designated as a poor imitation of the isocratic style would rather be self-adjustment and a certain fidelity to traditional forms of the historiographical genre.

Keywords: Ephorus, Isocrates, rhetorical historiography.
\end{abstract}

Recibido: 01-12-2014 Informado: 20-12-2014

Definitivo: 13-04-2015

Los oradores de la Antigüedad otorgaron a la historia una altísima valencia retórica ${ }^{1}$. Los hechos históricos aparecen principalmente en sus discursos en forma de lo que la rhetorica recepta ha denominado exemplum² (Lausberg 1975-76, \$\$ 410-426; Albaladejo 1989, 98-99). Y es que, como de-

${ }^{1}$ Este trabajo se enmarca dentro del proyecto «Retórica e Historia. Los discursos parlamentarios de Salustiano de Olózaga (1847-1871)», subvencionado por el Ministerio de Ciencia e Innovación (Ref. FFI2011-23519). Dejamos constancia de nuestro agradecimiento a esta institución.
2 El ejemplo (exemplum) constaría de una fuente material (res gesta), una función utilitaria (utilitas ad persuadendum) y una forma literaria (commemoratio) (cf. Quintiliano, Institutio oratoria, V, 11, 6). 
jara bien fundamentado Aristóteles en su Retórica, el recuerdo en el discurso de un hecho o de un personaje conocido del pasado puede encajar perfectamente en la estrategia argumentativa del orador con vistas a la persuasión ${ }^{3}$. Se trataría de invocarlo como precedente para justificar una tesis; o podría inducir a la identificación entre aquel suceso o aquel personaje del pasado dotados de prestigio y los del presente sometidos a la causa, de manera que ambos reciban la misma valoración, o, simplemente, suceso y personaje se aducirían como modelos para excitar a una acción o a un comportamiento similar. Es por ello por lo que también Aristóteles reconoce lo útil que es para el orador el conocimiento de «los escritos históricos de aquellos que escriben sobre las acciones de los hombres» (Retórica 1360a 35-37).

En la historia, en efecto, los oradores podían fundar exempla evocadores de hechos o personajes del pasado que tienen no solo efecto sobre la razón, sino también sobre los sentimientos y sobre el placer: docere/probare, movere et delectare, por usar la terminología latina tradicional que expresa las funciones o deberes del orador con respecto al oyente ${ }^{4}$.

No es de extrañar, así pues, que el gran Isócrates, fundador en el siglo IV a.C. de una de las más célebres escuelas de retórica en la Antigüedad, donde se formaba a los hombres retórica y moralmente para la discusión y la acción en el terreno de lo práctico, concediese al estudio de la historia una gran importancia. En uno de los discursos que dedica a Nicocles ${ }^{5}$, rey de Salamina en Chipre y discípulo suyo a la sazón, aconseja precisamente el tipo de conocimientos que debe adquirir un gobernante y cita, entre otros, el conocimiento del pasado, de los sucesos y de sus consecuencias ${ }^{6}$. Apoyándose en las lecciones del pasado y en su recuerdo, el gobernante puede cambiar el presente y tomar las mejores decisiones con respecto al futuro. Isócrates mismo incorpora y reconstruye en sus discursos, que servirán de modelos para el aprendizaje de sus discípulos, no solo episodios de naturaleza histórica, sino también consideraciones relativas al modo de integrar en la estructura argumentativa del propio discurso dichos episodios ${ }^{7}$.

La historia, así pues, dado su valor paradigmático, ha intervenido en la retórica desde antiguo y gozó de una amplia presencia y un gran prestigio en el currículo de las escuelas a través de ejercicios como la etopeya, la descripción o la narración, que contribuyeron por añadidura a fijar en la memoria personajes y hechos históricos relevantes ${ }^{8}$.

\footnotetext{
3 El estagirita distingue dos especies de ejemplos: la que consiste en referir un hecho que ha sucedido antes y la que inventa uno mismo. Considera más útil para el discurso la primera especie «dado que la mayor parte de las veces lo que va a suceder es semejante a lo ya sucedido"; solo habría que acudir a la segunda especie, en forma de parábolas y fábulas, cuando sea difícil encontrar hechos sucedidos que sean semejantes (Retórica 1394a 1-10). Salvo que se indique lo contrario, las traducciones de los textos de autores antiguos que citamos a lo largo de este artículo son nuestras.

4 No entramos en la discusión sobre el sesgo político o la mayor o menor tergiversación de los hechos aplicados por el orador a su relato. Puede verse, en general, los estudios de Nouhaud 1982 y de Worthington 2002.

5 Isócrates hace protagonista a este rey chipriota de dos discursos y le dedica un tercero sobre su padre. Son los titulados A Nicocles, Nicocles y Evágoras y los tres están bien imbricados por su función y por su contenido
}

en la escuela y en el programa educativo de Isócrates (véase el clásico libro de Jaeger 1962; en especial, el capítulo III, 4). Con estas obras comienza también toda una literatura en los más variados formatos destinada a la educación de los príncipes, de rica y larga tradición posterior.

6 Isócrates, $A$ Nicocles 35.

7 Es programático, en este sentido, el exordio del Panegírico, donde el rétor ateniense dice que los hechos pueden expresarse de muchas formas en los discursos e, incluso, podrían ser alterados e interpretados de distinta manera si el kairós lo requiere. Véase, en general, sobre las innovaciones y la influencia de Isócrates en los gustos estéticos del siglo IV a.C. Nicolai 2004.

8 Es interesante señalar que el florecimiento de las escuelas de retórica en las épocas helenística y romana, reconocida la utilidad de la historia y de la historiografía para suministrar exempla, llevó parejo el incremento de manuales sintéticos de contenido histórico (Ático, Cor- 
Pues bien, hemos estudiado en otros trabajos ${ }^{9}$ ese itinerario que va desde la historia a la retórica para comprobar cómo la oratoria política se sirve del exemplum histórico y lo integra en el tejido argumentativo y estilístico del discurso. Pero nos interesa ahora mostrar cómo también aquella téchne rhetoriké sistematizada y enseñada por los sofistas en el siglo $\mathrm{v}$ a.C. influyó no solo en la forma de relatar los hechos históricos sino incluso en la propia selección del material historiable, porque también la historiografía necesitó cada vez más de los recursos de la retórica para agradar y convencer a sus lectores. Nos referimos a aquella Retórica que, después de los sofistas, pasa a enseñarse y a ser aprendida en las escuelas; la retórica que López Eire, para distinguirla de la más intuitiva y menos formalista "Retórica de la oralidad», denomina «Retórica de Hermes», que será la que con el tiempo acabe triunfando como modelo formativo en la Antigüedad e implicando a todos los géneros literarios tanto en prosa como en verso ${ }^{10}$.

Y es también el gran Isócrates quien más contribuyó a la difusión de esa retórica escolar, una retórica que «trata de cuestiones políticas y que, a la vez que enseña a evitar el hiato, orienta el carácter del aprendiz de orador hacia los principios que deben presidir toda la formación moral que se requiere para el ejercicio de la Política Ética» (López Eire 2008b, 2). Isócrates, en efecto, había sido discípulo del sofista Gorgias y concebía la retórica como una preparación para la vida pública, en cuanto que enseñaba a reflexionar, a hablar de manera apropiada y bella, a convencer y a actuar. En el discurso que tituló Antídosis (Sobre el cambio de fortunas) podemos leer la más explícita exposición y defensa de sus principios pedagógicos, basados en la «enseñabilidad» (didaktón) de la virtud y el valor formativo del estudio de la Retórica:

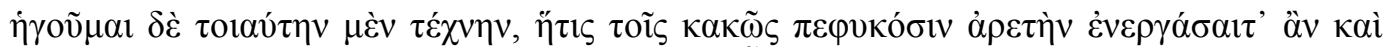

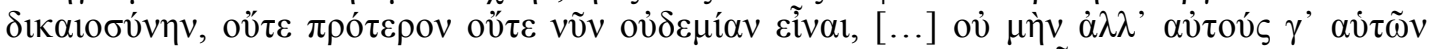

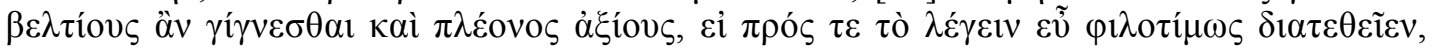

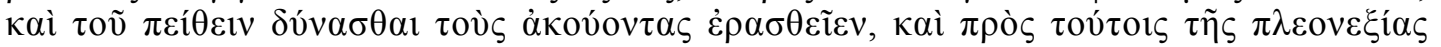

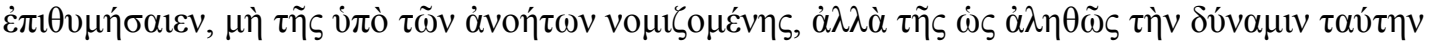

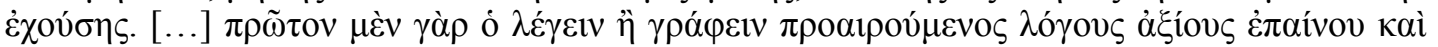

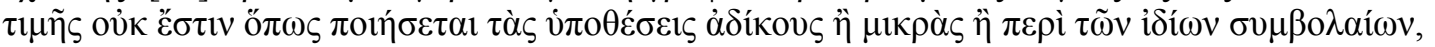

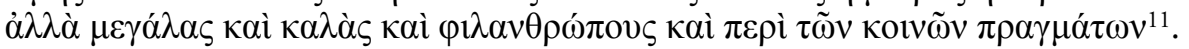

nelio Nepote, Varrón), epítomes de obras históricas de grandes dimensiones (Polibio, Salustio, Tito Livio), colecciones de excerpta (Polibio) o colecciones de hechos y dichos memorables (Valerio Máximo) con el objetivo de favorecer su aprendizaje y su uso en los ejercicios de escuela (progymnásmata) y en los discursos reales o ficticios (Cf. Nicolai 2007).

9 Cf. J.A. Caballero, «De la historia a la retórica: el uso del exemplum en la oratoria política», en L. Puig (ed.), Retórica, argumentación y politica: lecturas e interpretaciones, México D.F., UNAM, en prensa.

10 Cf. López Eire 2008a, 80: «La Retórica viva y conectada íntimamente con los usos y costumbres de la ciudad y la vida pública va a desaparecer para convertirse en una Retórica escolar, la "Retórica de Hermes", que se enseña y se aprende en la escuela, institución que estaba bajo la advocación de Hermes, una Retórica que, marcadamente influida por Isócrates y la escuela, es didáctica, filantrópica, moral, fuertemente epidíctica, indiferente a la separación tajante de oralidad y escritura, abierta por igual a griegos de linaje y helenos de cultura (paideía), abarcadora de todos los géneros literarios en prosa, como el de la Historiografía, y competidora y rival de la poesía, sobre la que va a triunfar y de cuyas funciones es o, por lo menos, pretende ser, heredera y sustituta».

11 Isócrates, Antídosis 274-276: "Considero que una técnica capaz de introducir la prudencia y la justicia en quienes carecen de dotes naturales para la virtud no ha existido ni antes ni ahora; [...] pero se harán mejores y más dignos si pusiesen su empeño en hablar bien, si deseasen poder convencer a sus oyentes y si, además, buscasen la superioridad, no la que piensan los insensatos, sino la que tiene realmente ese poder. [...] Cuando uno se propone pronunciar o escribir discursos dignos de elogio y honor, no puede usar argumentos injustos, poco importantes o sobre cuestiones privadas, sino temas importantes, hermosos, que beneficien a la humanidad y traten sobre asuntos públicos». 
Es comprensible, así pues, que Éforo, quien, si no fue discípulo directo de Isócrates, recibió una fuerte influencia del rétor ateniense (Nickel 1991, 233-239) ${ }^{12}$, diera al relato historiográfico una orientación retórica en el sentido de las enseñanzas isocráticas. Esto es, en sus manos, el relato historiográfico adopta los artificios estilísticos de la elocuencia con el objetivo de hacerlo eficaz a la par que más agradable a sus destinatarios, a quienes había que persuadir no solo por la fuerza de los argumentos y de los ejemplos, sino también mediante el uso de recursos expresivos acordes con su sensibilidad estética. En su preocupación por la actuación del individuo, el historiador aportaría sus juicios valorativos sobre los personajes y sus acciones, con vistas a su aprovechamiento pedagógico. Queda a salvo, por lo tanto, aquel valor utilitario, paidéutico, de la historia proclamado por Tucídides $^{13}$, que, en este caso, adquiere tintes marcadamente morales, hasta el punto de que muchos estudiosos ańaden como rasgo asociado a la retórica en esta historiografía del siglo iv a.C. las frecuentes valoraciones éticas de los personajes por parte de los autores con el propósito de profundizar en las motivaciones psicológicas de los hechos y de colaborar en la regeneración de la pólis desde las actuaciones individuales (Marincola 2001, 110-112; Pownall 2003, passim). Éforo mismo habría proclamado ese valor pedagógico de la historia sobre otras materias en el prólogo de sus Historias (cf. el conocido fragmento con la digresión acerca de la práctica de la música por los arcadios que se adscribe a esa parte de la obra: FGrHist 70, F 8 y el certero comentario de Nicolai 2013, 221-222).

Veamos cómo se sustancia esa nueva orientación del relato historiográfico en la obra de nuestro historiador, que, lamentablemente, nos ha llegado de forma fragmentaria.

Éforo ${ }^{14}$ había nacido en Cime, ciudad situada en la Eólide de Asia Menor, en torno al año 405 a.C. Acerca de su vida, el dato más repetido por los testimonios antiguos es su estancia en la escuela de Isócrates. Fue admirado en la antigüedad por haber sido el primero en componer una «historia universal» ${ }^{15}$ (es lo que le reconoce Polibio, V 33, 2 = FGrHist 70, T 7), citada con el tí-

12 Dionisio de Halicarnaso (Sobre Iseo 19, I pp. 121,18.12,17 Usener-Radermacher = FGrHist 70 T 24a y FGrHist 115 T 20 b) es el primero en referirse a Éforo, y también a Teopompo, como imitadores del estilo de su maestro, un estilo que se caracteriza por el uso de la escritura "periódica» y de los recursos expresivos tendentes a lograr la eufonía (evitación del hiato, «figuras gorgianas", etc.; cf. Norden 2000, 148-159; Gray 1987, 467-486). La filiación escolar directa ha sido puesta en duda por algunos estudiosos. Véase recientemente Parmeggiani 2011, passim. Sobre el estado de la cuestión, puede verse el artículo de V. Parker 2011, sobre Éforo en Brill's New Jacoby.

13 Con Tucídides se inicia el concepto paidéutico y utilitario de la historia al considerar la guerra del Peloponeso y las distintas calamidades que analiza en su libro como una lección para el futuro (Historia de la guerra del Peloponeso I, 22, 4: «Mi obra ha sido compuesta como una adquisición para siempre más que como una pieza de concurso para escuchar en un momento»). Esa concepción pragmática de la historia llegará a Roma, donde Cicerón la deja formulada para la posteridad con su conocida expresión historia magistra vitae (Cicerón, Sobre el orador II, 36).
${ }^{14}$ Los testimonios y fragmentos conservados de Éforo los recopiló F. Jacoby en su monumental Die Fragmente der griechischen Historiker (FGrHist) con el número 70. Aunque algo antigua, sigue siendo básica sobre Éforo la monografía de Barber, 1935, quien reivindica la obra del historiador de Cime frente al poco aprecio que eminentes filólogos como Schwartz, Laqueur y Jacoby tributaron a las cualidades historiográficas de los historiadores del siglo IV a.C. Más reciente es el extenso y riguroso estudio de G. Parmeggiani 2011, que pasa revista a las diversas interpretaciones que sobre la personalidad y la obra de Éforo se han realizado desde el siglo xix. También reciente es el estudio, traducción y comentario publicado por V. Parker (2011) en Brill's New Jacoby, s. $v$.

15 Este «universalismo», imitado en la época helenística y en la imperial romana por Polibio, Diodoro de Sicilia, Nicolás de Damasco, Pompeyo Trogo y Estrabón, entre otros, abrió una nueva y original orientación metodológica en la investigación histórica llamada a tener una gran transcendencia en la historiografía occidental. Sobre las diferencias entre el «universalismo» de Éforo y de Heródoto, considerado el más inmediato precedente en esta cuestión, puede verse Breglia 2005. 
tulo de Historias, que sería su gran contribución al ideario panhelenista de su maestro Isócrates, pues, en cierto modo, constituye una historia común de todos los griegos desde los tiempos más antiguos $^{16}$.

De Historias conservamos unos doscientos fragmentos (FGrHist 70, F 7-96 y 109-221); muchos son simples referencias toponímicas procedentes de los léxicos bizantinos y los pasajes más sustanciosos proceden de Ateneo y de Estrabón. Nos interesan especialmente los textos que se presentan como citas literales, verbatim, porque son los que reproducirían con mayor fidelidad las formas y los contenidos de la obra de nuestro historiador. Y en ellos se observa, ciertamente, la impronta que la retórica escolar de Isócrates dejó en Éforo, aunque en una intensidad distinta a la que se esperaría y — podríamos decir- autorregulada en el sentido que veremos más abajo.

Como discípulo de Isócrates, el rétor que marcó — no hay que olvidarlo — un hito decisivo en la evolución de la prosa artística griega (Nicolai 2004), se espera que Éforo siga al maestro en la evitación del hiato, en su gusto por las cláusulas rítmicas y, sobre todo, en el uso de la llamada por Aristóteles $\lambda \dot{\varepsilon} \xi 1 \zeta \kappa \alpha \tau \varepsilon \sigma \tau \rho \alpha \mu \mu \varepsilon ́ v \eta$ o «estilo periódico», hipotáctico o subordinante; el estilo que, aplicado ya en la oratoria por Trasímaco de Calcedón, fue llevado a su máxima expresión por Isócrates. En la descripción que nos ofrece el propio Aristóteles en su Retórica (1409a 35), la $\lambda \varepsilon \dot{\varepsilon} \xi 1 \varsigma \kappa \alpha \tau \varepsilon \sigma \tau \rho \alpha \mu \mu \varepsilon ́ v \eta$ despliega frases que corresponden a pensamientos, divisible en periodos, o sea elocuciones que tienen un principio y un fin en sí mismas y una dimensión abarcable con la vista. En virtud de su mayor complejidad formal, las cláusulas $(\kappa \tilde{\omega} \lambda \alpha)$ que componen dichos periodos pueden estar en una relación de analogía, contraste, antítesis, etc.; y sometidas a parísosis (cláusulas de la misma longitud) o a paromeosis (cláusulas que empiezan o terminan con sonidos similares), con la virtud de que, en todo momento, se perciben con claridad las diversas unidades del relato y su conjunto. Por todo ello, considera Aristóteles que este tipo de elocución es más agradable y perfecto que el llamado

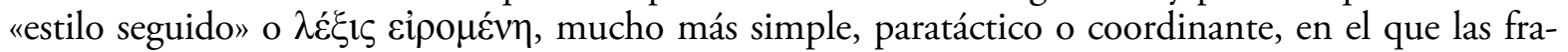
ses se suceden en pie de igualdad y sin formar una unidad, y no concluyen a menos que lo haga el asunto narrado (Retórica 1409a 16 ss.). Demetrio (Sobre el estilo I, 12-14), por su parte, también hace de Isócrates el principal promotor del estilo «enlazado» (periódico), aquel — describe Demetrio- que empieza con una idea a la que se subordinan otras para regresar, al final, a la idea inicial, el que «se parece a las esculturas de Fidias, que revelan a la vez grandeza y perfección»; y no el estilo «suelto» (paratáctico) de Hecateo o de Heródoto, en el que las ideas simplemente se acumulan o unen mediante partículas coordinativas, «el estilo de tiempos antiguos que tiene algo de pulido y sin adornos, como las estatuas arcaicas, cuyo arte parece consistir en una gran sencillez».

Pues bien, el siguiente fragmento procedente del libro I de las Historias de Éforo, transmitido por el gramático alejandrino Harpocración (FrGrHist $70 \mathrm{~F} 9$ ), es un buen ejemplo de la influencia del nuevo estilo isocrático en la prosa historiográfica: evita el hiato, presenta un elegante y rítmico

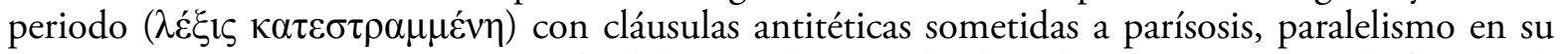
construcción sintáctica y un crescendo silábico en la segunda cláusula que contrapone de forma admirable los superlativos que expresan el pensamiento crítico de nuestro autor con respecto a la cre-

16 Se le atribuyen, además, una Historia local de Cime (FGrHist 70, F 1 y 97-103), destinada, seguramente, a promocionar la fama de su ciudad de origen —como hacían no pocos historiadores-, situando en ella nada menos que el nacimiento de Homero (F 1); un tratado Sobre inventos, en la línea de la pedagogía sofística de «popularización» del conocimiento (FGrHist 70,
F 2-5 y 104-106), y otro Sobre el estilo, muestra de sus preocupaciones retóricas (FGrHist 70, F 6 y 107-108). La Suda cita una obra Sobre virtudes y vicios en veinticuatro libros (FGrHist 70, T 1) de la que no se hace eco ningún otro autor en la antigüedad y que quizá no fueran sino colecciones tardías de excerpta procedentes de Historias. 


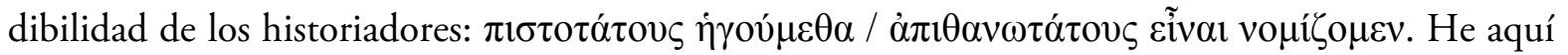
el fragmento completo:

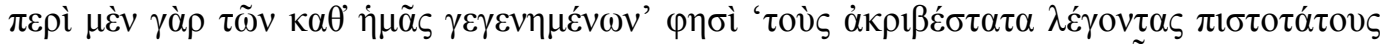

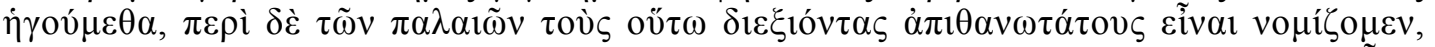

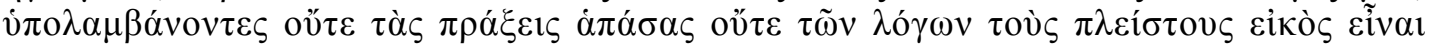

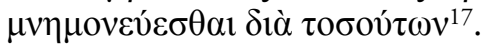

Es cierto que, al tratarse de un pasaje procedente del proemio, el lugar de la obra donde el autor expone sus reflexiones personales y polemiza acerca del método, la forma y el contenido, Éforo habría podido concitar ahí las mayores innovaciones formales porque es en los prólogos donde más patentes se hacen las carencias de los anteriores recursos de la prosa para la expresión de las ideas que los proemios solían recoger (Rodríguez Horrillo 2012, 441). Pero esta otra cita verbatim, extraída de una parte narrativa del libro XVIII y conservada por Ateneo (XI $500 \mathrm{C}=$ FGrHist 70 F 71), descubre también una composición cuidada, en un periodo que ilustra a la perfección la $\lambda \varepsilon \dot{\varepsilon} \xi ı \kappa \alpha \tau \varepsilon \sigma \tau \rho \alpha \mu \mu \varepsilon ́ v \eta$ con construcciones hipotácticas anudadas, frases y cláusulas en paralelo, antítesis y sinónimos:

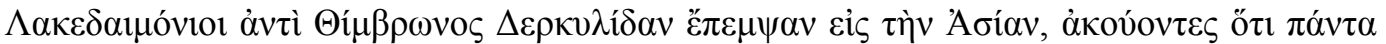

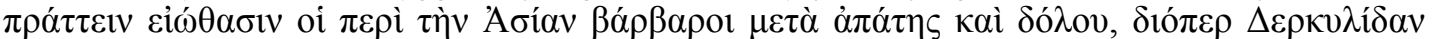

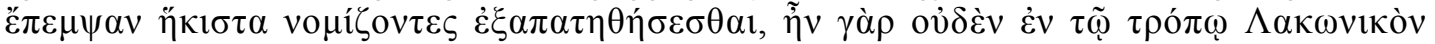

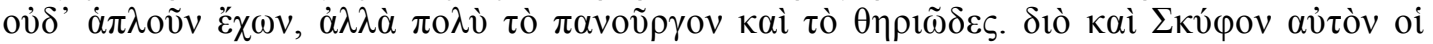
$\Lambda \alpha \kappa \varepsilon \delta \alpha$ นóvioı $\pi \rho \circ \sigma \eta \gamma o ́ \rho \varepsilon v o v^{18}$.

Obsérvese la amplificatio de carácter etopéyico referida al espartano Dercílidas, al que Jenofonte tan solo había calificado en sus Helénicas (III 1,8$)$ con un escueto «muy hábil» ( $\left.\mu \alpha \lambda_{\lambda} \alpha \mu \eta \chi \alpha v 1 \kappa o ́ s\right)$, que, al igual que el siguiente ejemplo traído por Estrabón (Geografía IX 2, 2 = FGrHist 70, F 119), muestra cómo las Historias no se limitaban solo a narrar los hechos políticos y militares de griegos y bárbaros. Éforo daba cabida a todo tipo de digresiones amplificadoras del relato, en las que quedaba reflejada su propia postura intelectual de acuerdo con los presupuestos isocráticos.

El fragmento en cuestión describe la geografía de Beocia y el historiador de Cime aprovecha para emitir su particular juicio sobre las causas del fracaso de Beocia como gran potencia, a pesar de la excelente disposición geográfica de la que gozaba, y de la efímera hegemonía sobre Grecia detentada por Tebas. El fracaso se atribuye por nuestro autor a la exclusiva atención que prestaron los tebanos a la formación militar, despreocupándose de «las letras y del conocimiento del hombre»:

”Е

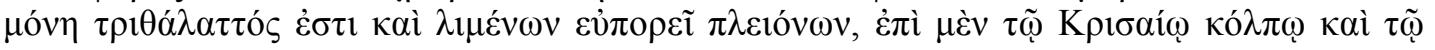

17 FGrHist 70 F 9: "Así pues, con respecto a los hechos acaecidos en nuestro tiempo» - afirma (sc. Éforo)_ «consideramos más fidedignos a quienes los relatan con la mayor precisión; pero con respecto a los hechos antiguos, creemos que no son en absoluto fidedignos quienes así proceden, porque suponemos que no es lógico que se recuerden después de tantos años ni la totalidad de los hechos ni la mayoría de los discursos».
18 FGrHist 70 F 71: «Los lacedemonios en lugar de Timbrón enviaron a Dercílidas a Asia, al oír que los bárbaros de Asia acostumbran a hacerlo todo con engaño y trampa; por eso enviaron a Dercílidas, creyendo que no se dejaría engañar lo más mínimo, pues no era en su carácter nada laconio ni simple comportándose, sino que era mucha su astucia y su brutalidad. Por eso también los lacedemonios le llamaban Esquifo». Jacoby corrige la

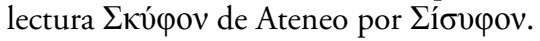




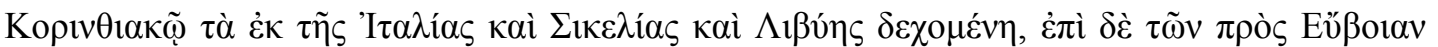

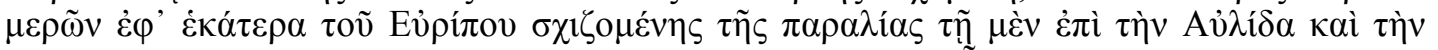

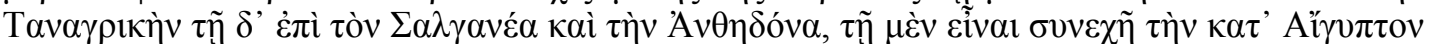

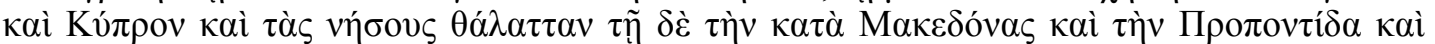

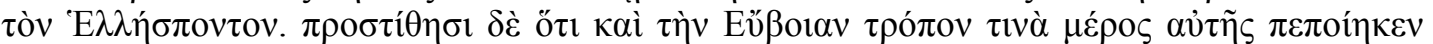

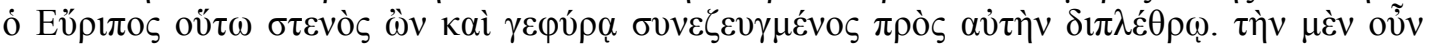

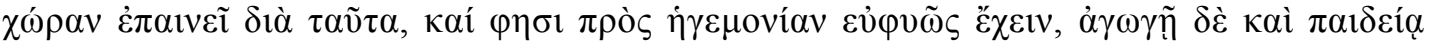

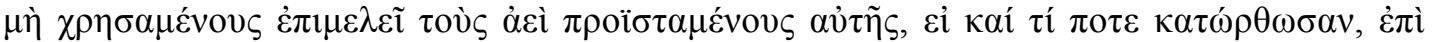

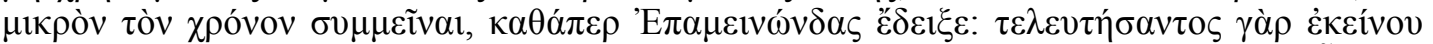

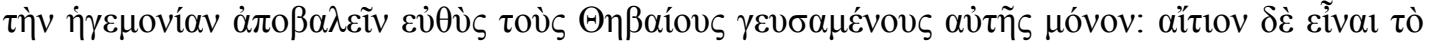

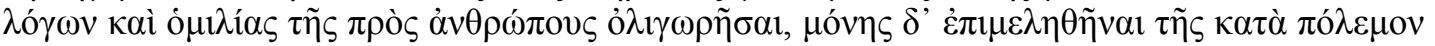
$\dot{\alpha} \rho \varepsilon \tau \tilde{\eta} \varsigma^{19}$.

La cita es recogida por Estrabón en estilo indirecto, pero trasluce no solo la ausencia de hiatos, sino también un extenso periodo que desarrolla, tras la descripción geográfica del país en construcciones paratácticas sencillas (véase infra), la valoración intelectual de Éforo por medio de oraciones subordinadas y construcciones participiales, hasta desembocar en una antítesis altamente relevante desde el punto de vista ideológico, porque es la primera vez en la historiografía que un autor pondera el valor de la paideía como factor de poder político frente a las virtudes militares ${ }^{20}$. Una paideía que se fundamenta, como la de Isócrates (Panegírico 49), en el aprendizaje del buen uso de las palabras y en el conocimiento de los demás seres humanos ${ }^{21}$.

Traemos a colación, por último, el famoso pasaje citado por Estrabón en Geografía X 4, 16 (= FGrHist 70 F 149) que contiene una de las digresiones más célebres de Historias: la que describe el peculiar modo de vida comunitario de los cretenses y su politeía. Para Éforo, la constitución política de los cretenses se fundamentaba en un principio básico: la libertad, que solo es posible preservar con la concordia entre los ciudadanos y el coraje frente a los enemigos; la primera se conseguiría por medio de la convivencia plena entre adultos y jóvenes y de un régimen de vida austero, que suprimiría las disensiones que se producen a causa de la codicia y el lujo; la segunda, mediante

19 FGrHist 70, F 119: «Éforo demuestra que Beocia es superior a los pueblos vecinos, no solo por esa (sc. fertilidad de su suelo), sino también porque es el único país que tiene tres mares y se beneficia de un mayor número de puertos; en los golfos de Crisa y de Corinto recibe los productos de Italia, de Sicilia y de Libia, mientras que por las partes que miran a Eubea, puesto que su costa está dividida en los dos sectores de una y otra parte del Euripo, por un lado el sector de Áulide y el territorio de Tanagra y por el otro el de Salganeo y Antedón, el mar queda abierto en un caso a la navegación rumbo a Egipto, Chipre y las islas, y en el otro rumbo a Macedonia, la Propóntide y el Helesponto. Y añade que en cierta manera el Euripo ha hecho de Eubea parte de Beocia, al ser tan estrecho y estar unido a ella por un puente de dos pletros. Así, pues, elogia el país por estas razones y dice que por naturaleza está bien dotado para la hegemonía, pero que quienes sucesivamente estuvieron al frente de ella no se preocuparon de la formación del espíritu y la educación, y que por ello, aunque en ocasiones lograron algún éxito, solo pudieron mantenerlo por poco tiempo, como se demuestra en el caso de Epaminondas, pues, después de su muerte, los tebanos perdieron inmediatamente la hegemonía, sin haberla gustado apenas; y que la causa de esto fue que rebajaron la importancia de las letras y del conocimiento del hombre y únicamente se cuidaron de las virtudes militares».

20 En cierto modo, podría citarse a Tucídides como precedente, quien, en boca de Pericles en su famoso discurso fúnebre (II 41), atribuye la superioridad políticomilitar de Atenas a su superioridad cultural, al hecho

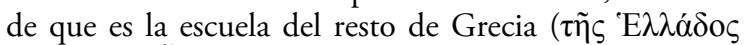
$\pi \alpha i ́ \delta \varepsilon v \sigma i v$ عĩv $\alpha i)$.

21 Nicolai $(2013,227-228)$ sitúa el origen último de este concepto, que concede el máximo valor paidéutico a las palabras ( $\lambda$ ó $\gamma 01$ ) frente a las armas, al ambiente cultural de aquellos filósofos que abandonaron la desacreditada denominación de «sofistas» para sustituirla por la de «rétores». 
un duro entrenamiento militar. Éforo constata la franca decadencia y descomposición del poder de Creta por causa de la cada vez mayor separación de sus ciudades con respecto a esa antigua politeía:

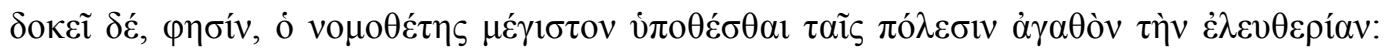

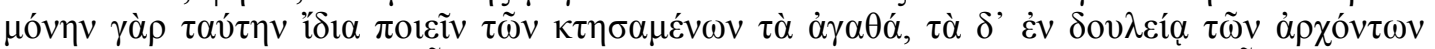

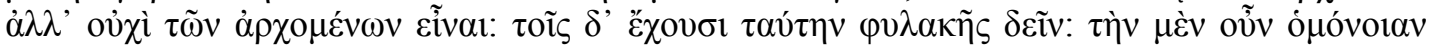

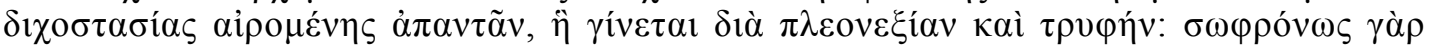

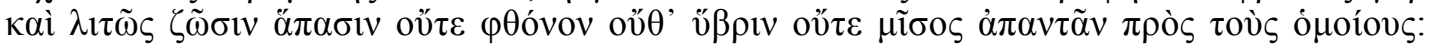

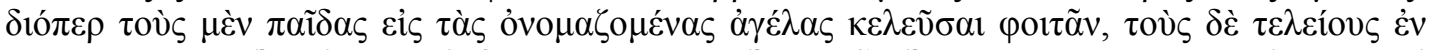

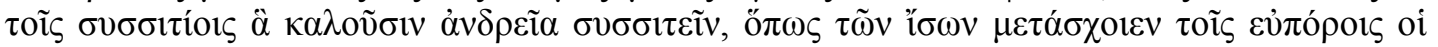

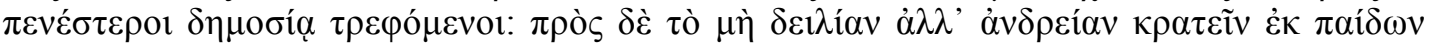

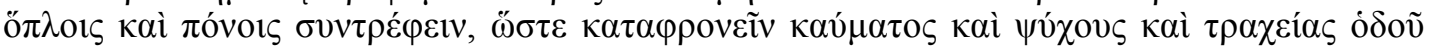

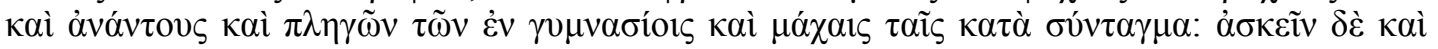

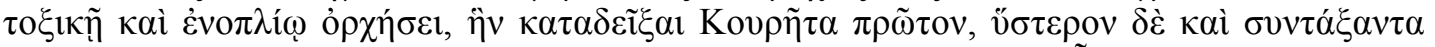

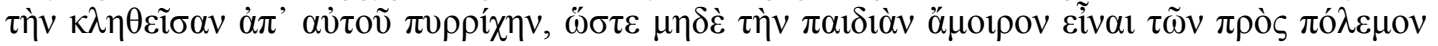

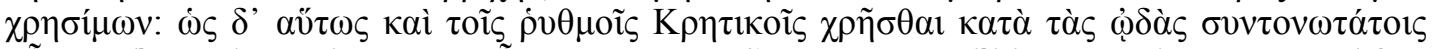

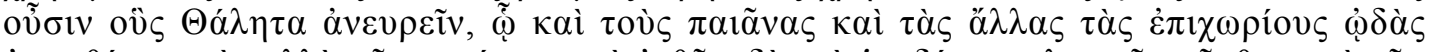

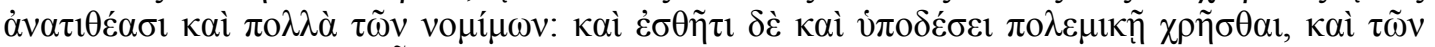

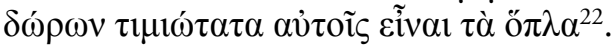

Las palabras de nuestro historiador citadas ahora por Estrabón reflejan de nuevo los dos rasgos esenciales de la prosa historiográfica de Éforo que comentamos: el valor ejemplarizante del relato y su cuidada redacción, con ausencia de hiatos (excepto alguno de artículo y nombre), y periodos formados a base de isócola y construcciones antitéticas donde se oponen los dos conceptos más importantes del párrafo (غ̇ $\lambda \varepsilon v \theta \varepsilon \rho i ́ \alpha$ frente a $\delta o v \lambda \varepsilon i ́ \alpha)$ y la manera, con el ejemplo de los cretenses, bien de preservar, bien de arruinar ese bien supremo para las ciudades que es la libertad. Es, así pues, otra clara ilustración de aquel estilo eurrítmico que habría aprendido de Isócrates y del propósito pedagógico de su relato. Esa idea, por cierto, de la comunidad de bienes y de la frugalidad en el régimen de vida como base de la concordia y de la libertad aparece tam-

${ }^{22}$ FGrHist 70 F 149: «Parece, afirma (sc. Éforo), que el legislador ha puesto como principio básico que el bien más importante para las ciudades es la libertad, pues solo ella hace que los bienes sean de propiedad privada de quienes los han adquirido, mientras que en una ciudad esclavizada son de los gobernantes, pero no de los gobernados. Pero es preciso que quienes poseen la libertad tengan la capacidad de preservarla, (y para ello son necesarias dos condiciones, la concordia entre los ciudadanos y el valor ante los enemigos). Pues bien, los ciudadanos llegan a la concordia mediante la supresión de las disensiones que se producen a causa de la codicia y el lujo, ya que cuando todos viven con moderación y frugalidad, no se provoca entre los iguales ni envidia ni arrogancia ni odio. Por esta razón la ley ordena que los muchachos frecuenten los grupos que los cretenses llaman agelas y que los adultos hagan sus comidas en común en los comedores colectivos que ellos llaman andreia, de modo que los más pobres, alimentados a expensas públicas, puedan es- tar en las mismas condiciones que los que disponen de medios. Y para que el valor prevalezca sobre la cobardía, la ley ordena que desde niños la educación se desarrolle en medio de armas y fatigas, de manera que aprendan a despreciar el calor y el frío, los caminos pedregosos y escarpados, y los golpes recibidos en los gimnasios y en los combates de los grupos en los que se adiestran; y que se ejerciten asimismo en el manejo del arco y en la danza armada, que dieron a conocer primero los Curetes y más tarde Pírrico, creador a su vez de la que en su honor recibió el nombre de "pírrica», de tal modo que ni sus mismos juegos son ajenos a lo que les es útil para la guerra. Por la misma razón en sus cantos usan ritmos créticos, ritmos muy vivos que inventó Taletas, a quien también se atribuye la invención del peán y de otros aires locales, así como la de muchas de sus costumbres; y asimismo tiene la misma explicación su uso de calzado y ropas militares, y el hecho de que entre ellos las armas son el más valioso de los regalos». 
bién en otra digresión del libro IV de Historias, también recogida por Estrabón (Geografía VII, 3,9 = FGrHist 70, F 42):

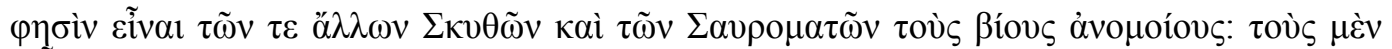

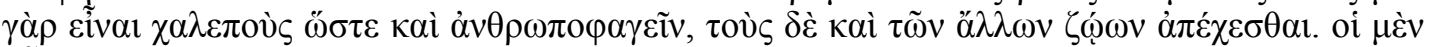

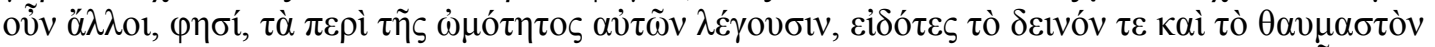

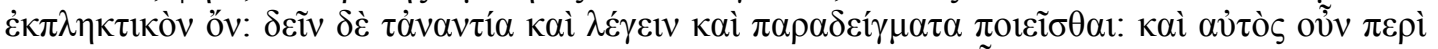

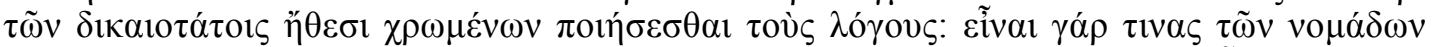

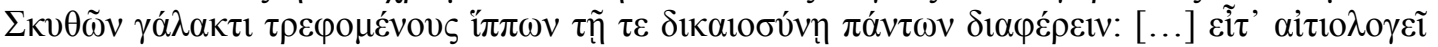

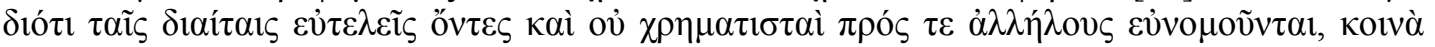

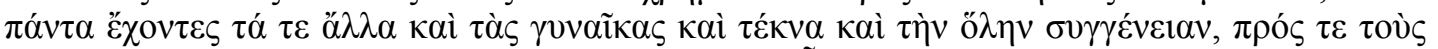

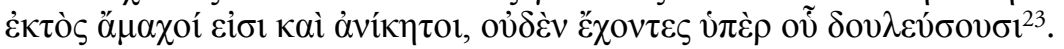

Está redactada con el mismo estilo eufónico y parecida complejidad sintáctica que el excursus sobre los cretenses. Pero ahora la digresión viene referida a un pueblo bárbaro, los escitas, y en ella se incluye una interesante, por poco común, valoración positiva de sus costumbres. Contra los escritores que tan solo habían destacado su crueldad y canibalismo, Éforo, basándose en los testimonios de Homero, Hesíodo y Quérilo, recupera la memoria de unos escitas «bebedores de leche» que más bien habría que adoptar como modelos, pues aventajan a todos por su sentido de la justicia. Además, escribe Eforo, «al ser sencillos en sus modos de vida y no dedicarse al comercio, gozan de buen gobierno entre sí, y, al tener en común todos sus bienes, mujeres, hijos y toda descendencia, son invencibles e irreductibles para los de fuera, ya que no poseen nada por lo que ser esclavizados».

A pesar de estos textos, que reflejan preocupación por la forma, estilo eurrítmico y construcción periódica, Éforo fue considerado por algunos críticos de la antigüedad un pobre imitador de Isócrates. Dionisio de Halicarnaso (Sobre Iseo $19=$ FGrHist 70, T 24a) calificó su estilo de pobre y poco ágil y recuerda aquella anécdota que hace de él un alumno menos avanzado que Teopompo, pues Isócrates «tenía que usar con Éforo la espuela y el freno con Teopompo; al uno lo frenaba exultante en su audacia verbal, y al otro, indeciso y como avergonzado, tenía que espolearlo» (FGrHist 70, T 28b).

Hay que considerar, no obstante, que en Éforo, por el carácter universal de su historia y por su particular metodología histórica en el uso de las fuentes antiguas ${ }^{24}$, han confluido obras de un buen número de autores anteriores cuyos textos ha podido citar verbatim. Y en esos textos no es

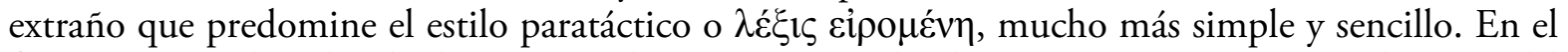
fragmento citado sobre la descripción de Beocia se puede observar, precisamente, que la parte del texto que refiere la situación geográfica de la región acumula un buen número de frases y sintag-

${ }^{23}$ FGrHist 70, F 42: «Afirma (sc. Éforo) que los regímenes de vida de los escitas y de los saurómatas son completamente distintos; unos, en efecto, llevan su crudeza hasta el punto de comer incluso carne humana, otros se abstienen de comer carne de otros animales. Otros historiadores, afirma (sc. Éforo), hablan de la crueldad de los escitas, conscientes de que lo terrible y lo maravilloso impacta. Pero hay que decir también lo contrario y ponerlos como ejemplo. Y habla entonces sobre aquellos escitas que tienen hábitos de lo más justo.
Entre los escitas nómadas, en efecto, algunos se alimentan de leche de sus yeguas y se diferencian de los demás por su sentido de la justicia. [...] Explica luego que al ser sencillos en sus modos de vida y no dedicarse al comercio, gozan de buen gobierno entre sí, y, al tener en común todos sus bienes, mujeres, hijos y toda descendencia, son invencibles e irreductibles para los de fuera, ya que no poseen nada por lo que ser esclavizados».

${ }_{24}$ Sobre el método y el criterio de Éforo en el uso de sus fuentes de información puede verse Parker 2004. 
mas unidos por partículas paratácticas que nos recuerdan las más sencillas construcciones sintácti-

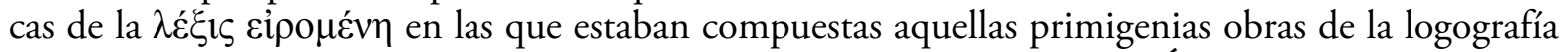
(López Eire 1985, 44). La sintaxis solo se vuelve más compleja cuando Éforo expresa su opinión personal sobre la forma de ser de los beocios (construcciones participiales, subordinadas concesivas, causales y sustantivas). Nuestro autor sería consciente, además, de que no está componiendo un discurso, sino una obra de historia (FGrHist 70, F 111) $)^{25}$; y lo que se señala como pobre imitación del estilo isocrático no sería sino autorregulación propia y cierta fidelidad a las formas tradicionales de sus fuentes historiográficas. No se puede negar por esta vía, como hacen algunos estudiosos, la influencia de Isócrates en el historiador de Cime (Parmeggiani 2011, 134). Es el maestro quien recomienda precisamente la adecuación del estilo a los hechos que se expresan ${ }^{26}$, a pesar de reivindicar, en la estela de Gorgias, los mismos recursos de la poesía para la prosa con el propósito de hacerla psicagógica, «arrastradora de almas». Éforo, como historiador, busca el empleo moderado de recursos literarios que hagan el relato historiográfico más atractivo y más acorde a los gustos estéticos de los lectores del siglo iv a.C., gustos estéticos en cuya conformación tanto había influido Isócrates (Nicolai 2004), pero sin desligarse enteramente de los condicionantes tradicionales del género historiográfico. Esos condicionantes de género que operarían sobre Éforo ya no lo habrían hecho sobre Teopompo, que abandonó el proyecto historiográfico de sus Helénicas para iniciar con sus Filípicas un tipo de obra histórica sin precedentes: de ahí la diferencia en los estilos de los dos discípulos de Isócrates.

Sea como fuere, la elaboración retórica del relato histórico y la tendencia a la emisión de juicios valorativos con vistas a la formación de los lectores son características destacadas de Éforo, y en ello coincide con los principales presupuestos educativos de la escuela isocrática y de su fundamentación retórica. Sin llegar a la deslumbrante exhibición de prosa de arte de Isócrates, en los fragmentos conservados apreciamos la ausencia de hiatos, las figuras usuales del lenguaje, la sinonimia, ejemplos de paralelismos, de antítesis, de cláusulas rítmicas, etc., rasgos que, sin duda, reflejan preocupación estilística. Además, de acuerdo con esa concepción didáctico-moral de la historiografía, nuestro historiador emite sus propias valoraciones sobre los más diversos asuntos y presenta modelos de conducta.

Pero esta orientación retórica y moral del historiador de Cime no implica una valoración despreciativa de su obra, a pesar de lo que opinaran al respecto algunos autores de la Antigüedad y también algunos críticos modernos porque piensan que la historia, para ser científica, debe prescindir de una visión ética de los acontecimientos y, en cuanto disciplina que busca la verdad, es incompatible con la retórica, que sería, por el contrario, el arte del engaño, de la manipulación y del $\operatorname{artificio~}^{27}$. El historiador Duris de Samos, por ejemplo, atribuye a Éforo y a Teopompo, una excesiva preocupación por la forma de escribir y les critica por no procurar la mímesis de la realidad que provoca el auténtico placer estético (FGrHist 76, F 1). Plutarco les reprocha asimismo a ambos (y a Anaxímenes, otro representante de la denominada "historiografía retórica») en sus Consejos políticos VI, 7 (Moralia $803 \mathrm{~b}=$ FGrHist 70 T 21) el exceso retórico de los discursos que reproducen

25 Es el tantas veces citado fragmento del proemio de Historias en el que Éforo reconoce que componer una obra histórica es mucho más difícil que componer un discurso epidíctico, lo que confirmaría que sus referencias a la hora de hacer esta valoración se basaban en su aprendizaje en la escuela de retórica (Breglia 2005, 280).
26 Isócrates, Evágoras 9-11.

27 U. von Wilamowitz y E. Schwartz popularizaron, por ejemplo, una visión despectiva sobre la labor historiográfica de Éforo, al que tachaban de mero compilador retórico más interesado en el embellecimiento estilístico que en la búsqueda de la verdad (Parmeggiani 2011, 11-12). 
en sus historias, poco apropiados en determinadas circunstancias ${ }^{28}$. Recientemente, Frances Pownall (2003, passim) intenta, por su lado, demostrar una relación causal entre la inexactitud histórica (o desviación de la tradición histórica aceptada) y el deseo del autor de moralizar. Y Giovanni Parmeggiani (2011, 34-66) duda del vínculo de Éforo — y también de Teopompo- con Isócrates basándose sobre todo en el rigor y método crítico con los que el historiador de Cime compuso su obra $^{29}$, como si estas cualidades fueran incompatibles con aquella filiación escolar. La orientación retórica del relato historiográfico no tiene por qué suponer la tergiversación de la verdad histórica, sino un modo distinto de contarla. La marca "historiografía retórica», que engloba a Éforo y aquellos otros historiadores que pretendidamente sustituyeron aquel tucidídeo afán por la verdad y el método con la querencia por la elaboración estilística y la calificación moral ${ }^{30}$, tiene precisamente en gran parte de la crítica un trasfondo despectivo con el que no podemos estar de acuerdo. Lo criticable no es que el historiador se sirva de la retórica para procurar a sus lectores una mejor y más agradable comprensión de los hechos que se relatan, sino cuando lo hace — como escribió Polibio (XXXVI 1, 6-7) — para hacer vana ostentación de sus habilidades elocutivas. Es verdad, no obstante, como afirma López Eire (2008b, 20), que la Historiografía, a partir de este momento, estará cada vez más al servicio de la Retórica, de la "Retórica de Hermes», tal como fuera concebida por Isócrates: educadora moral y políticamente, y propensa a mostrarse fuertemente epidíctica y literaria, hasta el punto de que para Cicerón el relato historiográfico estará ya plenamente integrado en el ámbito de la retórica, en general, y de la oratoria demostrativa, en particular ${ }^{31}$.

\section{BibLIOGRAFÍA}

Albaladejo, T., 1989, Retórica, Madrid: Síntesis.

Barber, G.L., 1935, The historian Ephorus, Cambridge: Cambridge University Press.

Breglia, L., 2005, «Eforo e il modello erodoteo», en: M. Giangiulio (ed.), Erodoto e il 'modello erodoteo'. Formazione e trasmissione delle tradizione storiche in Grecia, Trento: Università degli studi di Trento, 277-314

Gray, C., 1987, «Mimesis in Greek Historical Theory», AJPh 107, 467-486.

Iglesias-Zoido, J. C., 2007, «The Battle Exhortation in Ancient Rhetoric», Rhetorica 25, 141-158.

Jaeger, W., 1962, Paideia: Los ideales de la cultura griega, México: Fondo de Cultura Económica (=Berlin, 1933-47).

Lausberg, H., 1975-76, Manual de Retórica literaria, Madrid: Gredos (= München, 1960).

López Eire, A., 1985, «Formalización y desarrollo de la prosa griega», en: G. Morocho (coord.), Estudios de prosa griega, León: Universidad de León.

28 Se refiere Plutarco en concreto a las arengas que estos historiadores ponen en boca de los generales ante sus tropas ordenadas para la batalla y les aplica el siguiente verso de Eurípides: «Nadie hace esas estupideces junto a las armas». El admirado Tucídides, sin embargo, ya había hecho lo propio con los discursos pronunciados por los generales en circunstancias similares (cf. Iglesias-Zoido 2007, 141-158).

${ }_{29}$ El historiador de Cime pasa por ser, en efecto, uno de los autores más rigurosos (akribéstatos) de la antigüedad (FGrHist 70, T 14a y 16, testimonios, respectivamente, de Josefo y de Diodoro). Estrabón, por su parte, reconoce que utiliza a Éforo más que a ningún otro autor por el cuidado que aplica a su materia y conviene con el hipercrítico Polibio en que el de Cime aspiraba a la verdad por encima de todo, censurando a quienes introducían mitos en sus escritos históricos (Geografía IX 3, 11-12 = FGrHist 70, F 31b).

30 Cf. Peter 1911. Isócrates, Panatenaico 149-150, se ha tomado precisamente como manifiesto fundacional de esa historiografía retórica.

31 Cf. El orador 37 y 66; Sobre el Orador II, 36 y 62; Sobre las leyes I, 5. 
—,2008a, «Retórica e historiografía en Grecia», en: J.C. Iglesias Zoido (ed.), Retórica e historiografía en Grecia. El discurso militar en la historiografía desde la Antigüedad hasta el Renacimiento, Madrid: Ediciones Clásicas.

—,2008b, «La influencia de la Retórica sobre la Historiografía desde el Helenismo a la Antigüedad Tardía», Talia dixit 3, 1-32.

MarinCola, J., 2001, Greek Historians, New York: Cambridge University Press.

Nickel, D., 1991, "Isokrates und die Geschichtsschreibung des 4. Jhdts. v. Chr.», Philologus 135, 233-239.

NicolaI, R., 2004, Studi su Isocrate. La comunicazione letteraria nel IV sec. a.C. e i nuovi generi della prosa, Roma: Quasar.

—, 2007, «Storia e storiografia nella scuola greca», en: J.A. Fernández Delgado, F. Pordomingo, A. Stramaglia (eds.), Escuela y literatura en Grecia antigua, Cassino: Università di Cassino.

—,2013, "La storiografia di Eforo tra paideia retorica e identità greca», en: P. de Fidio, C. Talamo (eds.), Eforo di Cuma nella storia della storiografia greca. Atti del I Incontro Internazionale di Studi I (= La Parola del Passato 68), 217-240.

Norden, E., 2000, La prosa artística griega. De los orígenes a la edad augustea, México: UNAM (= Leipzig, 1898).

Nouhaud, M., 1982, L'utilisation de l'histoire par les orateurs attiques, Paris: Les Belles Lettres.

Parker, V., 2004, «The Historian Ephorus: His Selection of Sources», Antichthon 38, 29-50.

—,2011, «Ephoros», en: I. Worthington (ed.), Brill's New Jacoby, Leiden: Brill Online, s.v.

Parmeggiani, G., 2011, Eforo di Cuma: studi di storiografia greca, Bologna: Pàtron editore.

Peter, H., 1911, Wahrheit und Kunst, Geschichtschreibung und Plagiat im klassischen Altertum, Leipzig-Berlin: B.G. Teubner.

Pownall, Fr., 2003, Lessons from the Past: The Moral Use of History in Fourth-Century Prose, Ann Arbor: The University of Michigan Press.

Rodríguez Horrillo, M. A., 2012, Nacimiento y consolidación de la Historiografía griega, Zaragoza: Prensas de la Universidad de Zaragoza.

Worthington, I., 2002, «History and Oratorical Exploitation», en: I. Worthington (ed.), Persuasion: Greek Rhetoric in Action, London-New York: Taylor \& Francis. 